\title{
Stakeholder participation and sustainable fisheries: an integrative framework for assessing adaptive comanagement processes
}

\author{
Christian Stöhr $^{1}$, Cecilia Lundholm ${ }^{2,3,4}$, Beatrice Crona ${ }^{2}$ and Ilan Chabay ${ }^{5,6}$
}

\begin{abstract}
Adaptive comanagement (ACM) has been suggested as the way to successfully achieve sustainable environmental governance. Despite excellent research, the field still suffers from underdeveloped frameworks of causality. To address this issue, we suggest a framework that integrates the structural frame of Plummer and Fitzgibbons' "adaptive comanagement" with the specific process characteristics of Senecah's "Trinity of Voice." The resulting conceptual hybrid is used to guide the comparison of two cases of stakeholder participation in fisheries management - the Swedish Co-management Initiative and the Polish Fisheries Roundtable. We examine how different components of preconditions and the process led to the observed outcomes. The analysis shows that despite the different cultural and ecological contexts, the cases developed similar results. Triggered by a crisis, the participating stakeholders were successful in developing trust and better communication and enhanced learning. This can be traced back to a combination of respected leadership, skilled mediation, and a strong focus on deliberative approaches and the creation of respectful dialogue. We also discuss the difficulties of integrating outcomes of the work of such initiatives into the actual decision-making process. Finally, we specify the lessons learned for the cases and the benefits of applying our integrated framework.
\end{abstract}

Key Words: adaptive comanagement; fisheries; fisheries governance; learning; participation; stakeholder dialogue; Trinity of Voice

\section{INTRODUCTION}

The human overexploitation of natural resources has become one of the most critical challenges of our time. The question of how to limit the extraction by humans to a sustainable level falls within the broader issue of sustainable development, often defined as meeting "the needs of the present without compromising the ability of future generations to meet their own needs" (Brundtland 1987:23). It has in many cases been answered with the establishment of centralized, often high-level command and control structures. This strategy, however, has more often than not failed to achieve its objective, and is likely to be of limited success in a complex and changing world (Armitage et al. 2008). Complicating issues include an insufficient degree of certainty about ecological and social system behavior, widespread perceptions that the governance system lacks legitimacy, high regulatory costs of monitoring and enforcement in a culture of noncompliance, and loss of flexibility and resilience for adapting to changes in the social-ecological system. On the other hand, community management alone is unlikely to be able to address overarching issues of policy, property rights, and other effects that go beyond the community level (Plummer 2005). Thus, a combination of top-down and localized community management -often associated with the term "comanagement," and more recently "adaptive comanagement" - has been suggested as the way to successfully address environmental, economic, and societal concerns - the three pillars of sustainable environmental governance (Carlsson and Berkes 2005). Europe has seen an increasing interest in comanagement arrangements in fisheries management, although much remains to be improved (Österblom et al. 2011). However, published case studies of comanagement in European fisheries are rare because the European fisheries governance system is still, to a large extent, a command and control structure, and comanagement initiatives are limited to a few member states and/or a very local context (Symes et al. 2003). The lack of documented cases is problematic because it hampers our ability to assess the effectiveness of cooperative governance arrangements through cumulative case study research. Crosscomparison of multiple cases is therefore urgently needed.

Tools for comparing different cooperative governance scenarios are crucial for generating generalizable findings and enhancing our theoretical knowledge. We therefore integrate two complementary conceptual frameworks - adaptive comanagement (ACM) (Plummer and Fitzgibbon 2004) and the Trinity of Voice (TOV) (Senecah 2004) - to provide a more comprehensive framework for the analysis and evaluation of participation in environmental governance. The usefulness of the ACM approach is the explicit focus on preconditions and outcomes; however, the details of the ACM process, and how aspects of the process influence the nature and legitimacy of the outcomes, have been largely overlooked. TOV provides a detailed framework for analyzing the process characteristics in terms of (face-to-face) interaction and decision-making, and therefore allows a meaningful evaluation of participation in relation to outcomes. TOV ignores, however, contextual factors and has mostly been applied only to short-term public hearings. An integration of the two frameworks therefore promises to overcome the shortcomings of the individual approaches in a complementary way.

We apply this integrated framework in a comparative study of two cases of stakeholder participation in fisheries management where actors were engaged over several years. The analysis focuses on the context, as well as the process, and identifies critical factors

${ }^{1}$ Department for Applied IT, Chalmers University of Technology, Gothenburg, Sweden, ${ }^{2}$ Stockholm Resilience Centre, Stockholm University, Stockholm, Sweden, ${ }^{3}$ Centre for Teaching \& Learning in the Social Sciences, Stockholm University, Stockholm, Sweden, ${ }^{4}$ Department of Education, Stockholm University, Stockholm, Sweden, ${ }^{5}$ Institute for Advanced Sustainability Studies, Potsdam, Germany, ${ }^{6}$ Helmholtz Alliance on Sustainability and Social Compatibility of Future Energy Infrastructure, University of Stuttgart, Germany 
and incidents that supported or hindered the success of the two cases in relation to their expected outcomes and the overall governance performance.

\section{BACKGROUND AND THEORETICAL INTEGRATION}

ACM appears to have emerged from a project at the Center for International Forestry Research in 1997 to highlight the social context of adaptive management (sensu Lee 1993) but has since also come to represent an enrichment of comanagement scholarship in the directions of complexity science and resilience thinking (Plummer and Armitage 2007). ACM scholars point out that while the approach must be tailored to specific contexts (Armitage et al. 2009, Berkes 2009, Plummer and Hashimoto 2011), it can potentially address the problem of "fit" by, for example, enhancing the congruence between social institutions and biophysical systems (Olsson et al. 2007, Galaz et al. 2008), and can provide an arena in which to embrace uncertainty (Fennell et al. 2008) and build adaptive capacity (Armitage 2007, Fabricius et al. 2007).

As a concept, ACM is particularly concerned with governance through shared authority and decision-making, learning, and hence the ability to adapt to changing conditions (Plummer and Fitzgibbon 2004, 2006, Plummer and Armitage 2007, Plummer 2009). Various attempts have been made at organizing the complexities of the ACM process into conceptual frameworks to link together groups of variables that can be reliably assessed (e.g., Plummer and Fitzgibbon 2004, 2006, Plummer 2009). For example, the ACM process has been characterized as involving a number of phases, such as preparing the system for change by engaging actors and building networks, seizing windows of opportunity to affect change, and working to build the resilience of the governance system by continuous learning, negotiation, and experimentation (Olsson et al. 2004, Plummer 2009). This approach has a distinct focus on strategies of key actors involved but fails to capture the important contextual factors, which can be critical for understanding how initial conditions affect the emergence of collective action (c.f. Ostrom 2005, Brummel et al. 2012).

Another conceptualization of ACM describes it by means of three components: antecedents or preconditions, characteristics, and outcomes (Plummer and Fitzgibbon 2004). As many other ACM frameworks put forth, this approach is useful for organizing and thinking about the complex phenomenon of ACM, but it does not outline detailed mechanisms of causality, nor does it attempt to specify the values of independent variables, such as those outlined under preconditions and process characteristics, and how they contribute to outcomes. A recent review by Plummer et al. (2012) shows the lack of consensus around this issue. It thus seems fair to say that the ACM field still suffers from underdeveloped theories of causation that relate preconditions, process, and outcomes.

To address this shortcoming, we combine the conceptualization of preconditions, as described by Plummer and Fitzgibbon (2004), with a framework developed by Senecah (2004) that was originally designed for the structure and analysis of public hearings (Fig. 1). Senecah's framework, the Trinity of Voice, provides a template for designing and evaluating the efficacy of collaborative processes. It stresses the importance of public empowerment and focuses on the practical process of collaborative governance. Senecah argues that "the key to effective process is an on-going relationship of trust building to enhance community cohesiveness and capacity" (Senecah 2004:23). The approach rests on three concepts - access, standing, and influence - that need to be in balance to prevent tensions, limited effectiveness, and escalating conflicts.

Fig. 1. Conceptual framework integrating Adaptive CoManagement (ACM) and Trinity of Voice.

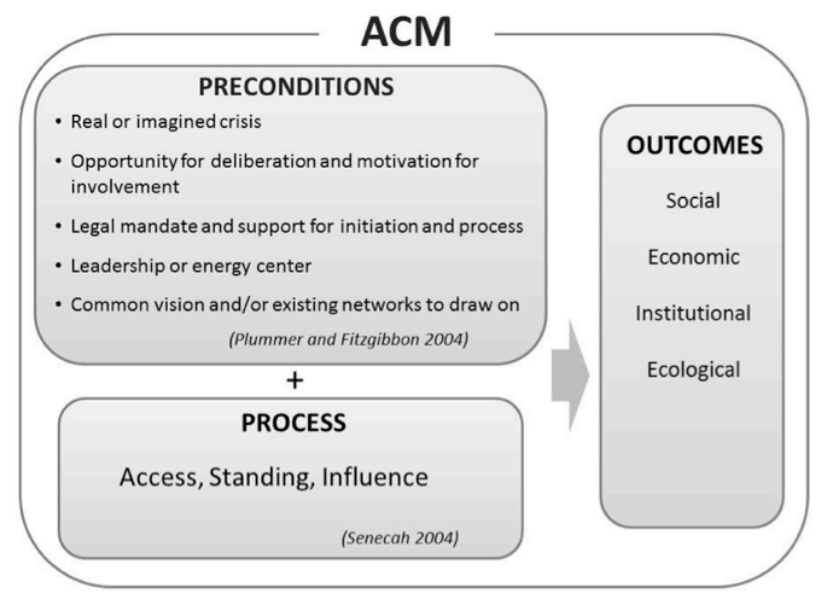

Access refers to actors' opportunity and potential for participation, safety of participation, and potential for being heard. It includes the chance to speak and express opinions, as well as the existence of sufficient support in terms of, for example, education and information, in order to be able to actively participate in the process. Standing is closely related to access and refers to the legitimacy of actors in the participatory exercise. It is concerned with the degree to which input by diverse stakeholders is taken seriously and their contributions are valued, respected, and honored (Walter et al. 2006:194). This can, for example, be achieved by focusing on interests rather than positions, including the development of an understanding of the drivers of those interests (Fisher et al. 1991, Senecah 2004). Influence relies on access and standing in participatory processes. It refers not only to the outcomes actors are trying to achieve but also whether the ideas of the participants were considered carefully together with those of others in processes where they matter. This might not result in stakeholders fully achieving their goals in the final decision, but they can achieve meaningful participation with opportunities for learning, pursuing mutual goals, and developing improvements (Walter et al. 2006:194).

Senecah (2004) suggests detailed conditions for each of these categories (Table 1) to allow for analysis of a participatory process, and the framework has been used to analyze and evaluate, among other things, stakeholder/citizen engagement in forest and sediment management (Walter et al. 2006), oil and gas-related disputes (Klassen and Feldpausch-Parker 2011), or urban ecosystem modeling (Thompson 2010). The TOV provides a useful grammar for examining the power and communication within the ACM process in more detail. 
Table 1. The Trinity of Voice (Senecah 2004).

\begin{tabular}{ll}
\hline \hline Categories & Grammar \\
\hline Access & Attitude of collaboration \\
& Convenient times \\
& Convenient places \\
& Readily available information and education \\
& Diverse opportunities to access information and \\
& education \\
& Technical assistance to gain a basic grasp of the issues \\
and choices & Adequate and widely disseminated notice \\
& Early public involvement \\
& Ongoing opportunities for involvement \\
& (Creative approaches to provide voice) \\
Standing & Opportunities for dialogue and deliberation \\
& Active listening \\
& Courtesy or an absence of discounting verbal or \\
nonverbal behavior & Early and ongoing voice \\
& Clear parameters for authority of participation \\
Clear parameters of investment & Collaborative room arrangements \\
Genuine empathy for the concerns of other perspectives, \\
dialogue, debate, and feedback \\
Meaningful decision space \\
Transparent process that considers all alternatives \\
Opportunities to meaningfully scope alternatives \\
Opportunities to inform the decision criteria \\
Thoughtful response to stakeholder concerns and ideas \\
\hline Influence
\end{tabular}

In sum, we combine past conceptual attempts at organizing the complexities of the ACM process with the TOV framework, which addresses how the process affects the nature and legitimacy of the outcomes. Together, this integrated framework allows us to compare two cases of collaborative governance of fisheries in Sweden and Poland that have data on social, economic, institutional, and ecological outcomes.

\section{APPROACH AND METHODS}

Our aim is not to test theory so much as to explore and add to suggested frameworks of causality in ACM, in the hope of taking us one step toward developing a theory of causal mechanisms that can be tested in the future. We do this by using the framework in Fig. 1 as a guide to examine each case, and then trace the pathways by which outcomes appear to have evolved.

The two case studies were undertaken independently of each other by two different research groups with similar yet not the same research objectives and approaches. The Polish case (herein referred to as PC) examined and was actively involved in the process of initiating and institutionalizing the Polish Fisheries Roundtable (PFRT) as a multistakeholder platform. The project was planned and implemented by a steering committee that consisted of actors from fisheries, environmental nongovernmental organizations (ENGOs), fisheries science, policy, and the research team. The objective was to create a platform that consisted of a diversity of relevant stakeholders that informs and influences decision-making in questions of Polish fisheries. It should also act as a cross-link between the local and national Polish level as well as European participatory forums such as the Baltic Sea
Regional Advisory Council. Our role was to help motivate stakeholders to participate and set up the Roundtable and its rules to foster productive dialogue and informed decision-making rather than the previous "shouting matches." This task was motivated by the insight that Polish fisheries resource managers and stakeholders lacked the skills to conduct effective participatory processes (see Hislop and Twery [2001] and Edwards and Smith [2011] for similar observations). Thus, we chose an action research approach (Rapoport 1970) with the PFRT as the action-orientated mechanism for the purposes of this study. Data were collected through participatory observation of nine PFRT meetings, as well as two meetings of the organizers and stakeholder groups. The meetings were audio-recorded, and parts were transcribed. The observations were supplemented by two rounds of semistructured interviews with fishery stakeholders, ENGOs, and scientists. In the first round (May 2008-May 2009), we conducted 28 interviews to study the context and preconditions of the existing Polish and international Baltic fisheries governance regime. In the second round (February 2010May 2010), nine interviews were conducted to assess the development and outcomes of the implemented PFRT process. The interviews asked for perceptions about the European and Polish fisheries governance system and its actors, science, and relation to governance and fishermen's knowledge, and as well as participation, including perceptions about different aspects of the PFRT process and its effects. Due to the participatory character of the research approach and the active involvement of the researchers in the initiation and establishment of the PFRT, the database also includes a significant number of informal talks with the PFRT members, email communications, a joint web-based forum, and other written documents.

The Swedish case (herein referred to as SC) was part of one of six Swedish comanagement initiatives supported by the former Swedish Board of Fisheries. The case was chosen on the rationale that it encompassed the highest diversity of stakeholders among the six pilot projects, including the state and local authorities. It concerns Lake Vättern, and the Lake Vattern Society for Water Conservation initiated the project. The organization was established in 1957 and comprises water- and fishing-related government bodies and businesses. In December 2005, the researchers contacted the chair and moderator of the project and in February 2006 were invited to a project meeting; they asked participants to consider giving permission to attend meetings, read protocols, and carry out interviews. After receiving approval, the researchers participated as observers of the comanagement meetings from 2006 to 2009. They attended all meetings in 2006 and until August 2007, and then subsequently once per year. After the management plan was approved in November 2009, interviews were conducted individually with all participants. The interviews focused on the participants' views of the participatory process and outcomes (social, ecological, and economical), and if they thought they had learned about ecological, social, or institutional aspects of fisheries as a result of taking part in the dialogues. Interview questions also considered the participants' differing views on the decline of fishing stock of Arctic charr (Salvelinus umbla) at the start of the project (2005) in comparison to the present (2010). Results concerning this aspect of "shared understanding" are reported elsewhere (Lundholm and Stöhr 2014). In total, 13 interviews were carried out over six months in 
2010; they lasted 60-120 minutes and were transcribed in full. As in the PC, the mix of sources proved fruitful in interpreting and analyzing interviews as the researchers had access to all meeting notes and had attended meetings; thus, they could confirm interview statements about the participatory process related to meetings and communicative aspects, such as the participants' views of the moderator's way of chairing the meetings, the allowance to speak, and their actual presence at meetings.

The processes under investigation have been running for two years with nine Roundtable meetings (PC) and four years with 20 meetings (SC). The cases can be compared through the application of the integrated framework because the dimensions are general enough to be examined in both cases but are sufficiently specific to meaningfully compare and relate the different dimensions of the different contexts/preconditions and processes to the observable outcomes of the two cases of stakeholder participation. To review the outcomes and assess to what degree they are likely to be linked to contextual factors and process elements in each case, we drew on the methodological approach of process tracing. Process tracing involves the examination of "diagnostic" pieces of evidence gathered through the different sets of qualitative data that contribute to supporting or overturning alternative explanatory hypotheses. The expected benefit of compromising generalizability through a small- $N$ case comparison (here $N=2$ ) lies in the opportunity to unfold more complex causal processes due to the richer set of observations (Hall 2003). A central concern is with sequences and mechanisms in the unfolding of causal processes over time, and the goal is to establish whether the events or processes within the case fit those predicted by alternative explanations (George and Bennett 2005, Bennett 2010). Considering our exploratory aim, we apply an inductive approach rather than testing different hypotheses. Although a potential limitation, this opened up the tracing process, and use of the two frameworks broadened and detailed the focus of our analysis. We attempted to identify the factors that have the largest causal relation to the observed outcomes, and discuss them in light of other findings in the literature.

The case study research in both cases was guided by slightly different research questions, objectives, and approaches. The research group in the Polish case was actively engaged in shaping the design and outcome of the participatory platform (Stöhr and Chabay, in press). Therefore, the Polish research team as active external actor is treated as one of the potentially influencing factors in the process tracing. The Swedish team took a more observational and nonparticipant role. However, attention from researchers could have influenced the actors under observation, for example, in terms of encouragement to attend meetings and carry on the project. This is known as the Hawthorne effect. We believe, however, that the presence of the researchers in the Swedish case was not influential enough to critically affect the outcomes. This was, for example, indicated by participants who perceived a critical event and were highly disappointed with the project outcomes of the meetings halfway through and considered withdrawing from the project. The applied qualitative methods in both cases involved interpretations of data that might have been biased by the researchers' own position in the field (e.g., Herr and Anderson 2005). The mixture of observation, semistructured qualitative interviews, and other methods attempted to minimize interpretation biases of the researchers by mixing the researchers' interpretations (i.e., comments based on observations) with interpretations of others (i.e., interviews).

The study of outcomes was necessarily constrained by several things: the difficulty in inferring causality between process and outcomes, and the fact that some outcomes may accrue over timescales much beyond the scope of this study. In fact, most outcomes are likely to change and evolve over time, and including a review of both short-term and long-term outcomes is likely to be essential to ultimately assess ACM initiatives (Plummer et al. 2012). While recognizing this severe limitation, we nonetheless attempted to summarize outcomes as captured through interviews and cross-validation through archival data and followup interviews. In other words, the outcomes presented were largely those defined by respondents.

\section{THE CASE STUDIES}

In this section, we provide information on the social and ecological context in which the two case studies are embedded.

(PC): The Baltic Sea is a comparatively small, semi-enclosed sea of about $415,000 \mathrm{~km}^{2}$ that supports both marine and freshwater species. The most important commercially harvested fish species are Atlantic cod (Gadus morhua), Baltic herring (Clupea harengus membras), and sprat (Sprattus sprattus), which make up about $90 \%$ of the total catches. While the Baltic herring and sprat stocks have generally been in good condition, the eastern of the two cod stocks had decreased considerably from about 700,000 tons at the beginning of the 1980 s to less than 100,000 tonnes in 2005 ([ICES 2012] though there have been signs of recovery in recent years). Following this general trend, the Polish catches of Atlantic cod declined from about 120,000 tons in 1980 to 9000 tons in 2008 (ICES 2012), a development that is the result of vanishing biomass as well as conservations measures enforced by the EU. Similar declines can also be identified for sprat and herring.

\section{Regulation and management}

EU member state Poland joined the Common Fisheries Policy (CFP) in 2004, and thereby transferred the fisheries management power to the European level (Burns and Stöhr 2011). The CFP provides regulations concerning all aspects of commercial fishing that are nationally implemented and enforced by the Polish Ministry of Agriculture. Scientific monitoring and advice is delivered mainly through the International Council for the Exploration of the Sea and is complemented by a number of stakeholder-based advisory groups, most notably, the Baltic Sea Regional Advisory Council.

At the national level, the Polish fishing industry underwent a severe destabilization through the transition from a socialist to a market-oriented society. The umbrella organizations that managed fisheries as local, cooperative organizations in the command economy before 1991 have almost completely disappeared, resulting in a highly fragmented organization of the fishing communities. The Polish fishing fleet consists of mainly small-scale fisheries distributed over 65 ports and small harbors. The fishery in Poland is a decreasing sector-while 1500 boats were registered in 1990, only 500 remained in 2010. Among the countries surrounding the Baltic, Poland has the highest amount of illegal, unregulated, or unreported fishing (Rossing et al. 2010), which led, for example, to a complete cod fishing ban imposed by the European Commission in 2007. 


\section{Stakeholders: interests and relations}

Interviews with stakeholders in Poland (e.g., fishers, ship owners, processing industry, NGOs) indicate that along with institutions, cultural norms of localized collaboration and mutual help vanished during the shift in political and market systems. In their place emerged an ideology of pure self-interested behavior and minimal legitimacy attributed to coordinating, regulating mechanisms (Marciniak and Jentoft 1997). In addition, Poland is characterized by an authoritarian culture, and both decisionmakers and stakeholders often have very little experience with deliberative decision-making. Skepticism and distrust towards the EU, the national administration, and science is especially high among Polish fishermen (Stöhr and Chabay 2010). Environmental NGOs, though fairly influential at the European level, still play a somewhat marginal role in Poland.

(SC): Lake Vättern, the geographical area of the Swedish study, is situated in the middle of four counties and eight municipalities in the south of Sweden. It is the sixth largest lake in Europe, covering $1912 \mathrm{~km}^{2}$, and is the second largest in Sweden. About 250,000 people are dependent on water from Lake Vättern for their daily consumption; fishing is another important resource (County Administrative Board in Jönköping county 2009). Lake Vättern is home to Sweden's largest and commercially most valuable stock of Arctic charr. Since the 1990s, there has been a strong decline in the charr stock, whereas the American crayfish (Pacifastacus leniusculus) stock has increased. The latter has generated significant income for both professional fishers and tourism linked to the crayfish fishery.

\section{Regulation and management}

Fishing in Lake Vättern is regulated by rules developed by the Swedish Agency for Marine and Water Management (SwAM), and is grounded in the national Fisheries Law. This law defines three categories, the two main ones being professional and recreational fishing (including sport fishing and fishing for subsistence), and fishing on private waters. Professional fishing requires a license, which is administered by the County Administration Board (CAB) and is decided by SwAM. Currently, 22 fishers are licensed to fish in Lake Vättern. Professional fishers and others are free to fish for all kinds of fish. However, time (i.e., seasonal closures), place (public or private waters), minimum fish size, and technical measures, such as gear and mesh size, are regulated by law.

The CABs (four around the lake) have the task of supervision, acting on behalf of SwAM, and are in charge of environmental monitoring and assessment. This is conducted in cooperation with The Swedish Agriculture University and the Lake Vättern Society for Water Conservation, an association created in 1957 to promote the maintenance of the lake ecosystem quality, and to coordinate monitoring, assessment, and scientific data collection.

\section{Stakeholders: interests and relations}

The number of stakeholders with an interest in the lake and its water are numerous, and their interests are not always compatible. For example, the public's need for clean water for households is in juxtaposition to more turbid and eutrophied waters that are beneficial to some fish species, but most important, there have been conflicts between recreational and professional fisher groups. In the past, meetings were held with all fishing groups, but they were discontinued in the 1990 s due to a national reorganization. Since then, the $\mathrm{CAB}$ fishery adviser has had regular but separate meetings with the different groups. Tension and mistrust have been growing within the fishing community and between the fishers and the national fisheries agency. This has also affected relations between $\mathrm{CAB}$ and the fishers. It is in this context that the Lake Vättern Society for Water Conservation and the four councils decided to move forward and apply to become a "Comanagement Initiative".

\section{RESULTS}

\section{Preconditions}

In the following, we outline the most important factors that led to the start of the two initiatives, and the motivations of the different groups of actors to participate and invest in the process.

\section{Real or imagined crisis}

(PC): The Polish process was preceded by an ecological crisis, especially with regard to cod, the most important commercially harvested fish species for Poland. Even from the institutional side it became apparent that the authoritarian structure of Polish culture made participation difficult in the more negotiation- and participation-oriented decision-making processes of the EU. Within Poland, the discussions were localized in smaller, common interest groups with limited perspectives. The communication within and among the different stakeholder groups was poor or nonexistent and characterized as "shouting matches" by several interviewees. Accordingly, consensus-based outcomes could very rarely be achieved. Together with other factors - the high amount of illegal, unregulated, or unreported fishing, the skepticism and distrust of Polish fisheries towards the EU and science, and not least, the collision course of the Polish government with the EU - this crisis helped stimulate willingness to experiment with a move toward a more collaborative process on the national level. Many of the participants in the Roundtable recognized the lack of good communication and expressed a need to improve it in order to achieve better results for all.

(SC): In Lake Vättern, the main ecological concern was a noticeable decline in Arctic charr, which is one of the characteristic species of the lake and an attraction for both commercial and recreational fishing (including sport fishing). This was of concern to all fishing-related stakeholders. Different reasons for the decline were suggested, but most respondents now agree that the major reason was fishing, in combination with reproductive failure related to climate change due to changed seasonal patterns in the icing of the lake. Thus, an ecological crisis also precipitated the initiation of this ACM process. In addition, growing distrust between fishing groups and county and national governments resulted in what can be termed an institutional crisis. This resulted in an emerging defiance of decisions and increasing noncompliance with rules and regulations, and led authorities to recognize the need for enhancing dialogue and conveying information to fishing groups. Until the beginning of the 1990s, a forum for communication between the authorities and fishing groups had been in place, but due to reorganization of the fisheries agency, it was canceled. Interviews with representatives of $\mathrm{CAB}$ indicated that this contributed to the emerging conflicts and mistrust, and the situation called for a new communication forum. 
Opportunity for deliberation and motivations for involvement A key for any comanagement initiative is the inclusion of most, if not all, relevant stakeholder groups. This is thought to enhance the legitimacy of both the process and outcomes (Dryzek 2000, Klijn and Edelenbos 2012, Sandström et al. 2014). Understanding the motivations behind stakeholder participation is therefore relevant. We elaborate on this for each case.

(PC): A passive approach (e.g., announcement of the multistakeholder forum only) was unlikely to motivate all relevant stakeholder groups-especially fisheries stakeholders-to participate. Through a previous project with the Baltic Sea Regional Advisory Council, the EU's stakeholder-based advisory forum for Baltic Sea fisheries, we developed and discussed the project idea with Polish key stakeholders. Those persons are trusted among their peers, so they could help motivate participants to join. In addition, we visited the harbors to speak to the fishermen about opportunities and benefits of participation. We were able to convene actors from fisheries, several ENGOs, science, and the Department of Fisheries of the Polish Ministry for Agriculture and Rural Development Administration to participate in the new forum. The CFP reform in 2012 served as a time-sensitive driver for action, creating both the pressure to start soon and the potential promise of gaining advantageous results for the fishermen within a limited amount of time if consensus advice could be achieved.

(SC): In 2004, the Swedish Board of Fisheries (now the Swedish Board for Marine and Water Management) initiated a comanagement project, and regional and local actors and institutions were invited to apply to become "pilot" projects. Representatives from the Lake Vättern Society for Water Conservation perceived this as an opportunity. The ecological and institutional crises provided the incentives for getting all fisher groups and other stakeholders to meet and submit a proposal for becoming a comanagement pilot area. Interviews show that an incentive for the fishing groups to participate in the comanagement process was a feeling that the process could be useful, and most importantly, decisions would not be made without their voices being heard. The groups that formed part of the comanagement initiative included professional and recreational fishers, CABs (two of four in order to diminish the representativeness of authorities), municipal representatives (two out of the eight around the lake, again to diminish the representativeness of authorities), scientists working for SwAM, water-owner representatives, and finally, a representative from the Lake Vättern Society for Water Conservation.

\section{Legal mandate and support for initiation and process}

(PC): The Polish government would have welcomed efforts to make the PFRT an official advisory body, and many of the fisheries stakeholders were striving for power gains. However, the steering committee decided that the PFRT in its original form would not have any formally defined influence in the decisionmaking process. This decision was grounded on the shared agreement that the PFRT would first have to focus on learning, trust building, and consensus finding to create the actual capacity for productive deliberation. A legally mandated role of the PFRT in the decision-making process from the beginning would have resulted in "power games" that most certainly would have undermined these efforts and only reinforced the pre-existing conflicts among the stakeholder groups.

(SC):In Lake Vättern, the issue of legal mandate created some confusion, which has had effects on the perceived legitimacy of the process. Many of the participants interviewed were incentivized to participate in the process by the hope of having their voices heard and incorporated into governance. This concerned a particular instance when the ACM initiative worked hard and prepared a document, which suggested regulations for fishing, only to realize they had no such mandate. This discrepancy between the perceived mandate between the ACM participants and the national Fisheries Board created anger and reduced incentives to stay involved.

\section{Leadership or energy center}

(PC): The idea of the PFRT initiative was initially introduced by two of the authors of this paper. Later, in order to build incentive for and energy in participation, but also to increase the legitimacy of the process, a steering committee was set up that consisted of the researchers, two Polish fishery and ENGO representatives in the Baltic Sea Regional Advisory Council, and a highly regarded scientist and Polish government advisor. Through this, stakeholders were assumed to get a sense of ownership of the initiative.

(SC): In 2004, in response to the call by SwAM for comanagement projects, the Lake Vättern Society for Water Conservation sent an application, and as the approval came, they met with all four CABs and the Fisheries Board. Initially, there was no funding connected to the initiative, but the group sent a supplementary application requesting funds. The Lake Vättern Society for Water Conservation, in close collaboration with the CABs, particularly Jönköping, thus showed strong leadership and created an energetic core around the ACM meetings.

\section{Common vision andlor existing networks to draw on}

(PC): By drawing on the different networks of the members of the steering committee and new PFRT members, the group developed a shared idea of the potential benefits of "improbable alliances" between formerly contesting stakeholder groups. In the first meetings, a common vision was created and documented in a Memorandum of Understanding. In short, it stated that the PFRT members would attempt to come to informed consensus (or disagreement) about different issues as an advisory input for decision-makers. However, it became an issue whether or not (and when) the PFRT should formally take positions at a later stage of the process.

(SC): Visions were somewhat different among the participants. Where some envisioned a management plan for the lake, others (the majority) thought the main purpose would be to enhance information and communication, and reduce conflict and mistrust. Eventually, however, through skilled leadership, the idea of a management plan was introduced when participants could agree on the usefulness of creating and writing such a plan.

\section{Process}

Table 2 presents and compares the characteristics of the process in the two cases in terms of elements of the TOV framework: 
Table 2. Process of the Swedish Co-management Initiative and the Polish Fisheries Roundtable according to the Trinity of Voice (Senecah 2004).

ACCESS

Attitude of collaboration Skilled "neutral" mediator as chairperson, keeping an attitude of collaboration among participants Benefits of collaboration and dialogue/mediation techniques introduced prior to the actual meetings Discussion and signing of a joint Memorandum of Understanding (MOU) that defines rules and procedures for dialogue

Convenient times and places

Date and time coordinated with the participants and invited experts

Accommodated at the Sea Fisheries Institute in Gdynia (now renamed as the National Marine Fisheries Research Institute)

Adequate and widely disseminated notice

Readily available information and education/ Diverse opportunities to access information and education/ Assistance to gain a basic grasp of the issues and choices

Dissemination of notice through various channels (email, a web forum, personal communication of the stakeholders with their community)

Documents prior to the meetings

Experts from both fisheries and science, covering a range of positions, to give presentations and provide on-hand expertise during discussions

Fishers were allowed the opportunity to voice their views and understandings of the diverse issues

Chairperson explaining and summarizing the issue and choices after complex presentations

Early involvement

Early involvement of diverse stakeholders via personal communication and a separate workshop

Ongoing opportunities for Long-term initiative with regular meetings on various involvement topics

STANDING

Opportunities for dialogue and deliberation

Regular multistakeholder meetings including government representatives

Groups' differing viewpoints were noted in the minutes/ record

Notes of the discussions were distributed to all participants, the Polish government, and via journal to fishermen

Consensus statement on individual transferable quota delivered to various public authorities on the national and EU level

Courtesy or an absence of Discussion rules agreed upon in the MOU to ensure that discounting verbal or nonverbal behavior, and active listening

Clear parameters of expectations for authority of participation

Clear parameters of investment

\section{active listing is encouraged and/or enforced}

Chairperson crucial to keep discussion focused and open

Objectives about the use of results not clearly enough defined and agreed upon in the beginning, with the result being that there was disagreement about how the outcomes should be used in policy-making processes

Clear expectations about the necessary financial and time expenditures by participants (e.g., number of meetings per year, travel, preparation, length of meetings) Participants cover their own travel and accommodation costs
Skilled "neutral" mediator as chairperson, keeping an attitude of collaboration among participants Benefits of collaboration and dialogue/mediation techniques introduced prior to the actual meetings

Date and time coordinated with the participants and invited experts

Accommodated at various places along the lake each time

Dissemination of notice through various channels (email, personal communication of the stakeholders with their community)

Documents prior to the meetings

Experts from the County Administration Board and scientists from the Swedish Board of Fisheries to give presentations and provide on-hand expertise during discussions

Fishers were allowed the opportunity to voice their views and understanding of the state of the lake and fish stocks Chairperson ensures all questions and uncertainty about what the information was conveying was clarified Fishers inform themselves on websites (Swedish Board of Fisheries and the Lake Vättern Society for Water Conservation)

Early involvement of all but the fisheries organizations in preparing for the comanagement projects

Long-term initiative with regular meetings on various topics

Groups' differing viewpoints were noted in the minutes/ record

Notes of meetings were distributed to all participants after the meeting, and were "approved" at the next meeting

Chairperson crucial in maintaining an atmosphere that would support dialogue and courtesy (e.g., humor to manage a sense of top-down/expert-novice imbalances) Making sure that everyone had a say after a presentation, or simply postponing decisions that were not at a stage of consensus

Objectives about the use of results not clearly enough defined and agreed upon in the beginning, with the result that some participants "lost" faith in the process

Mainly clear expectations about the necessary expenditures of time by participants (e.g., number of meetings per year, travel, preparation, length of meetings) Fishermen get reimbursed for costs (travel, loss of income (because fishers are not out fishing) and additional costs, such as parking fees (negotiated and settled every second year) 
Supporting arrangements for engaging dialogue and collaboration Genuine empathy for the concerns of other perspectives, dialogue, debate, and feedback
Round Table arrangement to indicate "equal voice" Coffee and lunch breaks for informal talks and trust building

Difficult to judge; discussion rules and mediation were supposed to overcome the clear existing lack of empathy
Round Table arrangement to indicate "equal voice" Coffee and lunch breaks and dinner for informal talks and trust building

Difficult to judge, but mediator made sure that communication between groups remained respectful and that gradual and mutual understanding of other perspectives increased

\section{INFLUENCE}

Meaningful decision space Some participants thought they would formally influence fishing regulations, but such was not the case

Process and meetings allowed for discussing alternatives of various aspects of fisheries and management Stakeholders continue to have difficulties understanding the rationale and ways government decisions are made The scope for decision space was not clearly communicated (and this caused problems)

Opportunities to meaningfully scope alternatives Opportunities to inform the decision criteria

Thoughtful response to stakeholder concerns and ideas relation to actual decision-making

Difficult to judge, though governance representatives were present at all meetings and expressed high appreciation for the Polish Fisheries Roundtable results

Government representatives provided response to

stakeholders' questions and concerns

Still lot of room for improvement about the use of this
Some participants thought they would influence fishing regulations, but such was not the case

Process and meetings allowed for discussing alternatives of various aspects of fisheries and management

The scope for decision space was not clearly communicated (and this caused problems)

Few opportunities to meaningfully scope alternatives in relation to actual decision-making

Decision criteria could have been more clearly specified by the government and communicated

The national Swedish Board for Marine and Water and their representatives could have been clearer in communicating the limits of influence on decision-making information in the decision-making process

access, standing, and influence. For each element, subcategories are provided following Senecah's (2004) specifications. The results presented in this table form the basis for the comparative discussion.

Both cases attempted to maximize access and standing by early involvement of key actors, convenient meeting arrangements, and widely distributed notice. Both processes were also supported by the provision of information and scientific expertise without restraining the participants' opportunities to present and express their views during the meetings. Interestingly, both cases undertook active measures to create and maintain a collaborative attitude and a productive discussion culture. A Memorandum of Understanding was even drafted and signed by participants in the PFRT to guide interactions. In Lake Vättern, the chairperson was recruited specifically for his perceived mediating skills. He was also perceived to be neutral; i.e., not involved in previous conflicts over interests around the lake and with SwAM. Given the past conflicts, tensions, and mistrust between the groups, the chairperson came to play a crucial role in maintaining an atmosphere that would support dialogue and courtesy. This was done by using humor and joking with representatives from the authorities; hence, managing a sense of top-down/expert/novice imbalance, but also making sure that everyone had a say after a presentation, or simply postponing decisions that were not at a stage of consensus at the closing of a meeting. So both cases stress the crucial role of the chairperson for both access and standing.

Both cases experienced struggles regarding influence. While within the process, a transparent and meaningful decision procedure was ensured, the relation to actual policy decisions was only vaguely or not defined. In the PFRT case, there was a vision to move slowly toward more influence once stakeholders gained the necessary capacity to participate in an effective way. This process, however, was difficult to define from the beginning, and after a few meetings, a conflict arose around this issue. More and more people felt that the PFRT should attempt to formulate jointly agreed upon positions and use them to influence decisionmaking on different levels. Others argued that the PFRT was still too fragile in terms of its capability to form consensus positions and might be misused by those in power. In the Swedish case, decision criteria and actual decision space were poorly communicated right from the beginning, which also resulted in different expectations and conflict. Several participants engaged in the ACM process with the belief that they would be able to influence fishing regulations, which was not the case. In reality, the ACM process in Lake Vättern involved limited devolution of actual power, and regulatory decisions were always retained at the national level (SwAM). Upon realizing this, several participants experienced great disappointment.

\section{Outcomes}

The third component of our analytical framework (Fig. 1) consists of outcomes (Table 3 ). We categorized them into four broad categories that - as will be evident in the later discussion - are mutually interlinked to various degrees. Table 3 also includes the kind and strength of evidence we found to support the given evaluations.

From Table 3, one can see that the most distinctive outcomes could be observed in the social category. They largely coincide with those highly cited in the literature, such as learning, conflict resolution, increased participation, collaboration, communication, and negotiation, all emerging in the systematic review by Plummer et al. (2012).

In neither of the cases did we see any discernible economic effects. This is partly linked to the recovery of the ecosystems, which 
Table 3. Outcomes of the Swedish Comanagement Initiative and the Polish Fisheries Roundtable.

\begin{tabular}{|c|c|c|c|c|c|}
\hline & Social & & Economic & Institutional & Ecological \\
\hline Trust & Communication & Learning & & & \\
\hline $\begin{array}{l}\text { POLAND } \\
\text { Continuity in meetings, } \\
\text { careful process design } \\
\text { and good leadership } \\
\text { have led to decreased } \\
\text { conflict and trust } \\
\text { among actors. } \\
\text { Likely to have built } \\
\text { capacity to deal with } \\
\text { future conflicts. } \\
\text { However, not certain } \\
\text { how representative trust } \\
\text { is for the broader } \\
\text { groups represented by } \\
\text { adaptive } \\
\text { comanagement (ACM) } \\
\text { participants. }\end{array}$ & $\begin{array}{l}\text { Atmosphere of free and } \\
\text { open discussion has } \\
\text { successfully been } \\
\text { implemented. } \\
\text { Capacity for } \\
\text { deliberation among } \\
\text { highly diverse } \\
\text { stakeholders increased. }\end{array}$ & $\begin{array}{l}\text { Quality of discussions } \\
\text { is perceived as high and } \\
\text { useful by all groups. } \\
\text { Representatives of all } \\
\text { groups indicate they } \\
\text { have learned from } \\
\text { others in the } \\
\text { discussions. }\end{array}$ & $\begin{array}{l}\text { Almost no discernible } \\
\text { economic effects. Some } \\
\text { information about } \\
\text { better use of existing } \\
\text { regulations for small- } \\
\text { scale fishermen. } \\
\text { Partly due to the longer } \\
\text { time-scales at which } \\
\text { such outcomes are } \\
\text { expected to be } \\
\text { generated, but also } \\
\text { because economic } \\
\text { outcomes are likely to } \\
\text { be affected by processes } \\
\text { at both geographic and } \\
\text { institutional scales } \\
\text { much beyond the Polish } \\
\text { Fisheries Roundtable } \\
\text { (PFRT). }\end{array}$ & $\begin{array}{l}\text { Long-term funding } \\
\text { from World Wildlife } \\
\text { Fund for Nature and } \\
\text { the Sea Fisheries } \\
\text { Institute has created a } \\
\text { relatively stable } \\
\text { institutional platform } \\
\text { from which to continue } \\
\text { the collaborative } \\
\text { process. }\end{array}$ & $\begin{array}{l}\text { Eastern cod stock has } \\
\text { undergone a tremendous } \\
\text { recovery, but this cannot } \\
\text { be linked directly to the } \\
\text { PFRT. } \\
\text { Stakeholders began } \\
\text { coconstructing } \\
\text { objectives. }\end{array}$ \\
\hline $\begin{array}{l}\text { Source and strength of evid } \\
\text { interviews, personal } \\
\text { impression- } \\
\text { medium }\end{array}$ & $\begin{array}{l}\text { ence } \\
\text { observation, personal } \\
\text { impression-medium }\end{array}$ & $\begin{array}{l}\text { interviews, personal } \\
\text { impression- } \\
\text { medium/strong }\end{array}$ & $\begin{array}{l}\text { observation, interviews } \\
\text { weak/medium }\end{array}$ & $\begin{array}{l}\text { interviews, personal } \\
\text { communication- } \\
\text { strong }\end{array}$ & $\begin{array}{l}\text { documents, observations } \\
\text { medium }\end{array}$ \\
\hline $\begin{array}{l}\text { SWEDEN } \\
\text { Continuity in meetings, } \\
\text { careful process design } \\
\text { and good leadership } \\
\text { have led to decreased } \\
\text { conflict and trust } \\
\text { among actors. } \\
\text { Likely to have built } \\
\text { capacity to deal with } \\
\text { future conflicts. } \\
\text { However, not certain } \\
\text { how representative trust } \\
\text { is for the broader } \\
\text { groups represented by } \\
\text { ACM participants. }\end{array}$ & $\begin{array}{l}\text { Atmosphere of free and } \\
\text { open discussion has } \\
\text { successfully been } \\
\text { implemented. } \\
\text { Capacity for } \\
\text { deliberation among } \\
\text { highly diverse } \\
\text { stakeholders increased. }\end{array}$ & $\begin{array}{l}\text { Quality of discussions } \\
\text { is perceived as high and } \\
\text { useful by all groups. } \\
\text { Investigations } \\
\text { undertaken within the } \\
\text { ACM initiative to } \\
\text { understand certain } \\
\text { ecological relationships } \\
\text { better. } \\
\text { Representatives of all } \\
\text { groups indicate they } \\
\text { have learned something } \\
\text { in the meetings, and } \\
\text { acknowledge increased } \\
\text { understanding of the } \\
\text { ecosystem and, in } \\
\text { particular, of various } \\
\text { fish species. } \\
\text { However, participants } \\
\text { agree that } \\
\text { "uncertainty" of system } \\
\text { dynamics (cause and } \\
\text { effect) remains a crucial } \\
\text { aspect in discussions } \\
\text { and decisions. }\end{array}$ & $\begin{array}{l}\text { No discernible } \\
\text { economic effects. } \\
\text { Partly, due to the longer } \\
\text { time-scales at which } \\
\text { such outcomes are } \\
\text { expected to be } \\
\text { generated, but also the } \\
\text { fact that certain } \\
\text { biophysical drivers (like } \\
\text { climate change) cannot } \\
\text { be addressed at the level } \\
\text { of the lake. }\end{array}$ & $\begin{array}{l}\text { Funding secured (in } \\
\text { 2009) from the EU and } \\
\text { European Fisheries } \\
\text { Fund (EFF) to } \\
\text { continue the ACM } \\
\text { work; funding of } \\
\text { meetings (as before) } \\
\text { and employment of } \\
\text { staff. Such local efforts } \\
\text { supported by the EFF } \\
\text { are envisaged to } \\
\text { contribute to realizing } \\
\text { the Common Fisheries } \\
\text { Policy objectives. } \\
\text { The ACM project } \\
\text { resulted in increased } \\
\text { compliance. }\end{array}$ & $\begin{array}{l}\text { Arctic charr stocks } \\
\text { reportedly increasing in } \\
2009 \text {, although reasons } \\
\text { are contested. Most } \\
\text { agree it is due to } \\
\text { permanent closed } \\
\text { fishing areas and } \\
\text { seasonal closures, in } \\
\text { addition to other } \\
\text { changes in fishing } \\
\text { regulations. }\end{array}$ \\
\hline $\begin{array}{l}\text { Source and strength of evid } \\
\text { interviews, personal } \\
\text { impression- } \\
\text { medium }\end{array}$ & $\begin{array}{l}\text { ence } \\
\text { interviews, observations } \\
\text { medium }\end{array}$ & $\begin{array}{l}\text { Interviews, observations } \\
\text { strong }\end{array}$ & $\begin{array}{l}\text { interviews, observations } \\
\text { medium }\end{array}$ & $\begin{array}{l}\text { interviews, personal } \\
\text { communication, } \\
\text { minutes from meetings } \\
\text { —strong }\end{array}$ & $\begin{array}{l}\text { documents- } \\
\text { medium }\end{array}$ \\
\hline
\end{tabular}


occurs over longer time frames than can be captured in this study. Both ecological and economic outcomes are also likely to be affected by processes at both geographic and institutional scales much beyond the level of the ACM partnership, such as biophysical drivers, like climate change or the inflow of Atlantic water into the Baltic basin, which affect reproduction and survival of charr and cod, respectively (Österblom et al. 2007). Institutional outcomes may be more easily dealt with. In both cases, longer term funding has been secured, thus allowing the ACM process to continue for the foreseeable future. Given the current lack of legal mandate, we cannot deduce any clear links between the ACM processes and policy impact.

Lastly, it is apparent from Table 3 that there is surprisingly little variation in the outcomes across cases. A critical examiner could determine the reason for this homogeneity is our focus on a narrow range of outcomes. However, while the broad groupings (social, economic, etc.) were used for classification, and while some of the nuances of each case are necessarily lost in a summary table, the outcomes in Table 3 were not predefined but emerged out of careful examination and cross-validation procedures.

\section{DISCUSSION}

In this section, we attempt to summarize the details of the circumstances surrounding the ACM processes in Lake Vättern and the PFRT initiative by drawing out the main differences and similarities while examining their likely contribution to the outcomes of each case. In doing so, it is useful to return to Fig. 1 , which outlines the integrated conceptual and theoretical hybrid that guided our assessment.

As noted by Plummer et al. (2012), understanding the causal relationship between components of the ACM process and outcomes remains a challenge. Tracing how the interplay between preconditions and process led to observed outcomes in our cases can thus take us one step in the direction of addressing this challenge.

Starting with social outcomes, the key elements emerging from both cases related to communication, learning, and trust. There is a rich literature on trust, which is relevant for this discussion. Scholars have argued convincingly that trust can be seen as both an outcome, thus emerging as a result of frequent interactions and previous trusting relationships (e.g., Dasgupta 1988, Hardy et al. 1998, Edelenbos and Klijn 2007), and an independent variable influencing governance outcomes (Klijn et al. 2012).

From the perspective of those who argue that trust can be created, it would seem that trust in both PFRT and Lake Vättern has been created in part by the regularity of meetings and the opportunity for deliberation (Table 1). Other process elements that appear to have contributed include explicit strategies to maintain an attitude of collaboration and respect, a courteous environment, and a transparent process that considers all alternatives suggested by participants. This corresponds well to Zucker's (1986) notion of process-based trust, which is tied to past or expected interaction processes and involves the incremental process of building trust through the gradual accumulation of either direct or indirect knowledge about the other. Opportunities for repeated formal and particularly informal contact between people are fundamental to developing trust as a property of the relationship. Confidence then can develop from repeated success in specific actions. Building of trust is thus seen as a gradual process, and the amount of trust conferred is expanded in incremental steps. But while trust can be created, it is also fragile and needs to be sustained and managed, and can diminish if rules are not in place to guide conduct and solve conflicts (Edelenbos and Klijn 2007). Both the PFRT and Lake Vättern process did consciously incorporate these elements, and stressed the crucial role of the chairperson in both cases and the Memorandum of Understanding in the PFRT process.

Koppenjan and Klijn (2004:69-70) proposed the term "governance networks" for situations of "more or less stable patterns of social relations between mutually dependent actors, which form around policy programs and/or cluster of means and which are formed, maintained and changed through series of games." This conceptualization seems highly appropriate as a term for the two ACM processes we examined. While trust can apparently be created, it is also hypothesized to affect network governance outcomes in several important ways. It is believed to (1) reduce transaction costs, (2) increase the probability that actors will invest resources in the joint initiative, (3) stimulate learning and exchange of information and knowledge, and (4) stimulate innovation (Klijn et al. 2012). Starting with the social outcomes, it appears that the three identified here are likely to be interrelated, such that the trust that emerged as a result of elements of the process (Table 2) has given rise to secondary outcomes related to communication and learning. Returning to some assumptions about this causal relationship, communication can be seen as prerequisite for learning, while learning itself is often seen as requiring frequent interaction among trusting parties (Reagans and McEvily 2003). It is thus clear that the causal relationship between the process elements and the outcomes of trust, communication, and learning is complex and multidirectional. But as noted, trust is also likely to have influenced other outcomes, such as compliance (SC), and most notably the willingness of actors to continue to contribute time and resources to the process, thus effectively determining longterm institutional outcomes, such as the persistence of the ACM.

Both ACM processes benefited from clear leadership. In Poland, this was represented by the steering committee, which consisted of well-respected individuals who were brought on board early in the process and who served to legitimize the process vis-à-vis other participants. In Lake Vättern, the Lake Vättern Society for Water Conservation, which had 60 years of collaborative experience, along with $\mathrm{CABs}$, provided a strong leadership role. Both cases also recruited chairpersons with good mediating skills, who were perceived as being neutral. This appears to have played an important part in bringing the participants "to the table" in the first place, and subsequently for contributing to specific process elements, such as promoting collaborative attitudes, courtesy, and respect.

So far, we have attempted to trace how elements of the process, captured through the framework of TOV, are likely to have influenced outcomes. But what about the contextual factors - or what Plummer and Fitzgibbon (2004) term “preconditions?" How have they affected the process and the outcomes? Scholars like Ostrom (2005) and North (1990) have argued that socio-political processes like comanagement of natural resources are played out in an institutional context of formal and informal rules that define 
the general conditions for collaboration. But while institutional arrangements are important, other contextual factors, such as the nature of the biophysical system in focus and socio-cultural particularities of the actors, can also be essential for understanding how the ACM process evolves and the outcomes it is able to achieve (c.f. IAD framework in Imperial 1999).

The real or imagined crisis, suggested by Plummer and Fitzgibbon (2004), is present in both cases we examined. Considerable decline in commercially important fish stocks triggered a sense of urgency among resource users and related stakeholders. In both cases, the perceived decline, combined with "external" actors (i.e., actors that were not part of the resource user groups), were important triggers for initiating collaborative processes. In Sweden, this is represented by the Lake Vättern Society for Water Conservation responding to the call by SwAM to start fisheries comanagement pilots and seizing this as an opportunity for collaboration among stakeholders. In Poland, it corresponded to the creation of the PFRT, emerging from a Baltic Sea Regional Advisory Council project.

Neither ACM case had a legal mandate to influence the governance process surrounding fisheries and lake management, although the cases differ in the degree to which this lack of mandate was explicitly made clear to the participants at the onset of the process. In Poland, this was in fact a strategic decision by the key individuals driving the process not to become an official advisory body until learning, trust, and the capacity for productive deliberation was enhanced. This decision was based on the insight that consensus-building processes require a negotiation dimension that can be a significant barrier to the legitimacy and learning effects of the participatory process (Schusler et al. 2003, Van den Hove 2006). Negotiation typically involves withholding of information deemed disadvantageous or potentially competitively advantageous at a later point in the negotiation. In a context of learning, the opportunity to discuss and gain understanding of contrasting views can occur outside the competitive arena, at least temporarily. Effective deliberation depends on a certain capacity. Otherwise, such platforms are in danger of being misused to only support and legitimize the decisions of those in power (Griffin 2010). Nevertheless, both cases experienced struggles around the wish of stakeholders to "gain influence" in the decision-making process at some point.

The creation of a common vision among the participants differed between the cases. The PFRT was partly created, and participants recruited, on the basis of a common vision, while in Lake Vättern, the goal of the process was less clear at the start, and visions therefore differed. Some participants envisioned a management plan for the lake, while others (the majority) thought the main purpose would be to enhance information and communication, and reduce conflict and mistrust. These divergent views eventually became clear, and through the skillful mediation of the chairperson were aligned, which enabled collaboration to continue.

A final important difference concerns the prior collaborative experience among participants in the two ACM processes. While this is not addressed in the framework proposed by Plummer and Fitzgibbon (2004), the critical role that previous collaboration might have on new organizational processes has been empirically demonstrated both at individual and structural levels (Ostrom
2005, Brummel et al. 2012). Previous, or existing, governance structures can provide or lend trust and legitimacy to new comanagement initiatives. However, in cases where previous collaboration processes have failed or been conflict ridden, these past experiences may instead constitute a significant obstacle in the struggle for successful and legitimate comanagement outcomes (Sandström et al. 2014). In Poland, cooperative structures for local fisheries management existed prior to the political reform of the 1990s but have almost completely disappeared, resulting in a highly fragmented condition of the fishing communities and little collaborative governance. The participants in the PFRT were thus largely novices to the process of collaboration and deliberative negotiation processes. In Lake Vättern, on the other hand, while not all of the participants had personal experience of collaboration, considerable experience can be said to exist through the leadership of the Lake Vättern Society for Water Conservation and their long experience of coordinating collaborative processes among various lake stakeholders.

\section{CONCLUSION}

We developed and applied a framework consisting of elements of adaptive comanagement and the Trinity of Voice, and compared two cases of fisheries-related ACM processes. This reflects our interest in bringing the development of theories of causal mechanisms in this field one step further along. The conceptual hybrid enabled us to trace pathways related to contextual and process factors and link them to outcomes. Focusing on participation in the ACM processes and using the TOV framework, thus looking in more detail at aspects concerning access, standing, and influence, has provided insights on how these various aspects are important for the outcomes.

For the Swedish case, we conclude that the use of the TOV framework has highlighted how access and standing were actively supported within the project and were important in bringing about the positive outcomes. Important examples include the compensation for travel costs and income losses when attending meetings (access), the protocols with detailed utterances when there were diverging views (standing), and the moderator who made sure all participants were allowed to speak and created a "respectful" attitude toward differing knowledge (standing). By looking finally at influence, we conclude that the participants perceived this aspect to be important. However, misunderstandings and lack of communication on this topic led to feelings that stakeholders' ideas were not carefully considered in the decisionmaking process, which could have jeopardized the ACM project (and positive outcomes). Influence was achieved in terms of mutual learning, with access and standing as important prerequisites.

The experiences of the Polish fisheries project stress the need for planning and forethought, which participatory processes often lack (Glicken 2000:308). This includes a particular focus on the process of communication, trust building, and learning in the beginning, and efforts to gain early successes, even if limited in scope, to gain momentum and investment. As in the Swedish case, the key role of a facilitator bringing together a plurality of legitimate views among participating actors was highlighted to achieve standing. Against the concern and experiences in the other case that a lack of influence would risk the stakeholders' willingness to invest and participate in the process (e.g., Maguire 
2003), we found that most stakeholders saw great benefits in terms of learning, trust, and capacity building. This lets us conclude that the explicit discussion of potential negative effects of visible and hidden power imbalances on a joint and productive exchange of knowledge (Schusler et al. 2003, Van den Hove 2006) can lead to a greater acceptance of a lack of actual decision-making power, at least for some time.

While the initial conditions regarding common views among participants and previous collaborative experience are quite different between the cases, they showed very similar outcomes in terms of trust, communication, and learning among the participants. Those can be seen as a primary and critical outcome, which in turn gives rise to multiple other outcomes and likely influences the degree to which interactions will be sustained for the benefit of the ACM process. They can be traced back to the combination of respected leadership, skilled mediation, and strong focus on deliberative approaches, and the creation of respectful dialogue (what Senecah refers to as "standing"). Though generalizations and comparisons with other research have to be treated with caution, the lessons learned are to a large extent consistent with those of others (e.g., see Reed 2008 for an overview). In particular, the cases as long-term efforts nevertheless support Senecah's (2004) presumption that meaningful participation has to build on access and standing in order to achieve meaningful outcomes. The findings also partly support her notion that influence, although important, involves more than decisions in favor of one's own interest only. Aspects of learning and trust building are important results and prerequisites for starting to codevelop objectives and the necessary capacity to participate meaningfully in the debates about complex and conflicted issues. An action- and learning-based approach provides the flexibility needed to adapt to the dynamics of the process in a challenging environment, where heterogeneous interests, capacities, and power structures create changing needs and priorities during the process (Reed 2008, Ravera et al. 2011).

We further conclude that our analysis has benefited from the hybrid conceptual framework. Despite the different original research designs of the two studies, it was possible to trace and compare characteristics of the contexts and processes and their contribution to outcomes. The ACM provided a larger frame in which long-term initiatives could be structured, and helped identify contextual factors, such as the combination of crisis and opportunity for deliberation as strong causal factors behind the creation of the ACM process in both cases. TOV enabled us to look beyond structural borders to process specifics to make judgments about whether or not participation was actually meaningful and what elements (or missing elements) of access and standing were most decisive in explaining the achieved results.

We note that for a theory of causality to be developed further, the outcomes would have to be more clearly specified, indicating the direction of change of outcome variables as conceptualized in relation to causal variables. Academic assessments of ACM processes generally suffer from the difficulty of assessing longer term outcomes, and hence understanding the relative causal strength between any of the process variables addressed here and outcomes at such large geographic and temporal scales. Our study is no exception. However, given the increasing focus on collaborative governance (Carlsson and Berkes 2005, Plummer et al. 2012) and governance through networks (Koppenjan and Klijn 2004), the existence and persistence of processes like the ones we examined will be an essential source to draw upon once the notion of collaborative governance actually becomes implemented throughout bureaucratic structures.

Responses to this article can be read online at: http://www.ecologyandsociety.org/issues/responses. $\mathrm{php} / 6638$

\section{Acknowledgments:}

We are grateful to the participants for allowing access to meetings and giving interviews, and to the editors and reviewers for their valuable feedback. We would also like to thank the County Administrative Board in Jönköping for information and assistance provided. This study was made possible thanks to funding by the Swedish Research Council and the Baltic Sea 2020 foundation.

\section{LITERATURE CITED}

Armitage, D. 2007. Building resilient livelihoods through adaptive co-management: the role of adaptive capacity. Pages 62-82 in D. Armitage, F. Berkes, and N. Doubleday, editors. Adaptive comanagement: collaboration, learning and multi-level governance. UBC Press, Vancouver, B.C., Canada.

Armitage, D., M. Marschke, and R. Plummer. 2008. Adaptive comanagement and the paradox of learning. Global Environmental Change 18(1):86-98. http://dx.doi.org/10.1016/j.gloenvcha.2007.07.002

Armitage, D., R. Plummer, F. Berkes, R. I. Arthur, A. T. Charles, I. J. Davidson-Hunt, A. P. Diduck, N. C. Doubleday, D. S. Johnson, M. Marschke, P. McConney, E. W. Pinkerton, and E. K. Wollenberg. 2009. Adaptive co-management for socialecological complexity. Frontiers in Ecology and the Environment 7:95-102. http://dx.doi.org/10.1890/070089

Bennett, A. 2010. Process tracing and causal inference. Pages 207 220 in H. Brady and D. Collier, editors. Rethinking social inquiry. Rowman and Littlefield, Lanham, Maryland, USA.

Berkes, F. 2009. Evolution of co-management: role of knowledge generation, bridging organizations and social learning. Journal of Environmental Management 90(5):1692-1702. http://dx.doi. org/10.1016/j.jenvman.2008.12.001

Brummel, R. F., K. C. Nelson, and P. J. Jakes. 2012. Burning through organizational boundaries? Examining inter-organizational communication networks in policy-mandated collaborative bushfire planning groups. Global Environmental Change 22:516528. http://dx.doi.org/10.1016/j.gloenvcha.2011.12.004

Brundtland, G. 1987. Our common future: report of the 1987 World Commission on Environment and Development. United Nations.

Burns, T. R., and C. Stöhr. 2011. Power, knowledge, and conflict in the shaping of commons governance. The case of EU Baltic fisheries. International Journal of the Commons 5(2):233-258. [online] URL: http://www.thecommonsjournal.org/index.php/ ijc/article/view/260/217 
Carlsson, L., and F. Berkes. 2005. Co-management: concepts and methodological implications. Journal of Environmental Management 75(1):65-76. http://dx.doi.org/10.1016/j.jenvman.2004.11.008

Dasgupta, P. 1988. Trust as a commodity. Pages 49-72 in D. Gambetta, editor. Trust: making and breaking cooperative relations. Oxford University Press, Oxford, UK.

Dryzek, J. S. 2000. Deliberate democracy and beyond: liberals, critics, contestations. Oxford University Press, Oxford, UK.

Edelenbos, J., and E.-H. Klijn. 2007. Trust in complex decisionmaking networks: a theoretical and empirical exploration. Administration \& Society 39:25-50. http://dx.doi. org/10.1177/0095399706294460

Edwards, V. M., and S. Smith. 2011. Lessons from the application of decision-support tools in participatory management of the New Forest National Park, UK. Environmental Policy and Governance 21(6):417-432. http://dx.doi.org/10.1002/eet.589

Fabricius, C., C. Folke, G. Cundill, and L. Schultz. 2007. Powerless spectators, coping actors, and adaptive co-managers: a synthesis of the role of communities in ecosystem management. Ecology and Society 12(1):29. [online] URL: http://www.ecologyandsociety. org/vol12/iss1/art29/

Fennell, D., R. Plummer, and M. Marschke. 2008. Is adaptive comanagement ethical? Journal of Environmental Management 88 (1):62-75. http://dx.doi.org/http://dx.doi.org/10.1016/j. jenvman.2007.01.020

Fisher, R., W. Ury, and W. Patton. 1991. Getting to yes. Second edition. Basic Books, New York, USA.

Galaz, V., T. Hahn, P. Olsson, C. Folke, and U. Svedin. 2008. The problem of fit between ecosystems and governance systems: insights and emerging challenges. In O. Young, L. A. King, and H. Schroeder, editors. The institutional dimensions of global environmental change: principal findings and future directions. MIT Press, Boston, Massachusetts, USA.

George, A., and A. Bennett. 2005. Case studies and theory development in the social sciences. MIT Press, Cambridge, Massachusetts, USA.

Glicken, J. 2000. Getting stakeholder participation 'right': a discussion of participatory processes and possible pitfalls. Environmental Science \& Policy 3(6):305-310. http://dx.doi.org/ http://dx.doi.org/10.1016/S1462-9011(00)00105-2

Griffin, L. 2010. The limits to good governance and the state of exception: a case study of North Sea fisheries. Geoforum 41 (2):282-292. http://dx.doi.org/10.1016/j.geoforum.2009.10.007

Hall, P. A. 2003. Aligning ontology and methodology in comparative politics. Pages 373-404 in J. Mahoney and D. Rueschemeyer, editors. Comparative historical analysis in the social sciences. Cambridge University Press, New York, USA. http://dx.doi.org/10.1017/CBO9780511803963.012

Hardy, C., N. Phillips, and T. Lawrence. 1998. Distinguishing trust and power in inter-organizational relations: forms and facades of trust. Pages 64-87 in C. Lane and R. Bachmann, editor. Trust within and between organizations: conceptual issues and empirical applications. Oxford University Press, Oxford, UK.
Herr, K., and G. L. Anderson. 2005. The action research dissertation. Sage, Thousand Oaks, California, USA.

Hislop, M., and M. Twery. 2001. A decision framework for public involvement in forest design planning. Final report prepared for Policy and Practice Division of the Forestry Commission, Forestry Commission, Roslin, Scotland.

Imperial, M. T. 1999. Institutional analysis and ecosystem-based management: the institutional analysis and development framework. Environmental Management 24:449-465. http://dx. doi.org/10.1007/s002679900246

International Council for the Exploration of the Sea (ICES). 2012. Report of the Baltic Fisheries Assessment Working Group 2012 (WGBFAS), 12-19 April 2012, ICES Headquarters, Copenhagen. ICES CM2012/ACOM:10.

Klassen, J. A., and A. M. Feldpausch-Parker. 2011. Oiling the gears of public participation: the value of organisations in establishing Trinity of Voice for communities impacted by the oil and gas industry. Local Environment 16(9):903-915. http://dx.doi. org/10.1080/13549839.2011.615305

Klijn, E. H., and J. Edelenbos. 2012. The influence of democratic legitimacy on outcomes in governance networks. Administration \& Society 45(6):627-650. http://dx.doi.org/10.1177/0095399712454113

Klijn, E. H., J. Edelenbos, and B. Steijn. 2012. Trust in governance networks: its impacts on outcomes. Administration \& Society 42:193-221.

Koppenjan, J. F. M., and E. H. Klijn. 2004. Managing uncertainties in networks: a network perspective on problem solving and decision making. Routledge, London, UK.

Lee, K. 1993. Compass and gyroscope. Island Press, Washington, D.C., USA.

Lundholm, C., and C. Stöhr. 2014. Stakeholder dialogues and shared understanding: the case of co-managing fisheries in Sweden. Sustainability 6(7):4525-4536. http://dx.doi.org/10.3390/ $\underline{\text { su6074525 }}$

Marciniak, B., and S. Jentoft. 1997. Fisheries management in post-communist Poland: prospects of user-participation. Ocean \& Coastal Management 34(1):73-89. http://dx.doi.org/10.1016/ $\underline{\text { S0964-5691(96)00074-9 }}$

Maguire, L. A. 2003. Interplay of science and stakeholder values in Neuse River total maximum daily load process. Journal of Water Resources, Planning and Management 129:261-270. http:// dx.doi.org/10.1061/(ASCE)0733-9496(2003)129:4(261)

North, D. C. 1990. Institutions, institutional change and economic performance. Political economy of institutions and decisions. Cambridge University Press, New York, USA. http://dx.doi.org/ http://dx.doi.org/10.1017/CBO9780511808678

Olsson, P., C. Folke, and F. Berkes. 2004. Adaptive comanagement for building resilience in social-ecological systems. Environmental Management 34(1):75-90. http://dx.doi.org/10.1007/s00267-003-0101-7

Olsson, P., C. Folke, V. Galaz, T. Hahn, and L. Schultz. 2007. Enhancing the fit through adaptive co-management: creating and maintaining bridging functions for matching scales in the Kristianstads Vattenrike Biosphere Reserve Sweden. Ecology and 
Society 12(1):28. [online] URL: http://www.ecologyandsociety. org/vol12/iss1/art28/

Österblom, H., S. Hansson, U. Larsson, O. Hjerne, F. Wulff, R. Elmgren, and C. Folke. 2007. Human-induced trophic cascades and ecological regime shifts in the Baltic Sea. Ecosystems 10:877889. http://dx.doi.org/10.1007/s10021-007-9069-0

Österblom, H., M. Sissenwine, D. Symes, M. Kadin, T. Daw, and C. Folke. 2011. Incentives, social-ecological feedbacks and European fisheries. Marine Policy 35(5):568-574. http://dx.doi. org/http://dx.doi.org/10.1016/j.marpol.2011.01.018

Ostrom, E. 2005. Understanding institutional diversity. Princeton University Press, Princeton, New Jersey, USA.

Plummer, R. 2005. A review of sustainable development implementation through local action from an ecosystem management perspective. Journal of Rural and Tropical Public Health 4:33-40.

Plummer, R. 2009. The adaptive co-management process: an initial synthesis of representative models and influential variables. Ecology and Society 14(2):24. [online] URL: http://www. ecologyandsociety.org/voll4/iss/art24/

Plummer, R., and D. Armitage. 2007. A resilience-based framework for evaluating adaptive co-management: linking ecology, economics and society in a complex world. Ecological Economics 61:62-74. http://dx.doi.org/10.1016/j.ecolecon.2006.09.025

Plummer, R., B. Crona, D. R. Armitage, P. Olsson, M. Tengö, and O. Yudina. 2012. Adaptive comanagement: a systematic review and analysis. Ecology and Society 17(3):11 http://dx.doi. org/10.5751/ES-04952-170311

Plummer, R., and J. Fitzgibbon. 2004. Co-management of natural resources: a proposed framework. Environmental Management 33 (6):876-885. http://dx.doi.org/10.1007/s00267-003-3038-y

Plummer, R., and J. Fitzgibbon. 2006. People matter: the importance of social capital in the co-management of natural resources. Natural Resources Forum 30:51-62. http://dx.doi. org/10.1111/j.1477-8947.2006.00157.x

Plummer, R., and A. Hashimoto. 2011. Adaptive co-management and the need for situated thinking in collaborative conservation. Human Dimensions of Wildlife Management 16:222-235. http:/l dx.doi.org/10.1080/10871209.2011.585434

Rapoport, R. N. 1970. Three dilemmas in action research: with special reference to the Tavistock experience. Human Relations 23 (6):499-513. http://dx.doi.org/http://dx.doi.org/10.1177/001872$\underline{677002300601}$

Ravera, F., K. Hubacek, M. Reed, and D. Tarrasón. 2011. Learning from experiences in adaptive action research: a critical comparison of two case studies applying participatory scenario development and modelling approaches. Environmental Policy and Governance 21(6):433-453. http://dx.doi.org/10.1002/eet.585

Reagans, R., and B. McEvily. 2003. Network structure and knowledge transfer: the effects of cohesion and range. Administrative Science Quarterly 48:240-267. http://dx.doi. org/10.2307/3556658

Reed, M. S. 2008 Stakeholder participation for environmental management: a literature review. Biological Conservation 141
(10):2417-2431. http://dx.doi.org/http://dx.doi.org/10.1016/j. biocon.2008.07.014

Rossing, P., S. Booth, and D. Zeller. 2010. Total marine fisheries extractions by country in the Baltic Sea: 1950-present. Fisheries Centre Research Reports 18(1):263. [online] URL: http://www. balticsea2020.org/english/images/Bilagor/total\%20marine \%20fisheries. pdf

Sandström, A., B. Crona, and Ö. Bodin. 2014. Legitimacy in comanagement: the impact of preexisting structures, social networks and governance strategies. Environmental Policy and Governance 24(1):60-76. http://dx.doi.org/10.1002/eet.1633

Schusler, T. M., D. J. Decker, and M. J. Pfeffer. 2003. Social learning for collaborative natural resource management. Society \& Natural Resources 16(4):309-326. http://dx.doi. org/10.1080/08941920309158

Senecah, S. L. 2004. The Trinity of Voice: The role of practical theory in planning and evaluating the effectiveness of environmental participatory processes. Pages 13-33 in S. P. Depoe, J. W. Delicath, and M.-F. A. Elsenbeer, editors. Communication and public participation in environmental decision making. SUNY Press, Albany, New York, USA.

Stöhr, C., and I. Chabay. 2010. Science and participation in governance of the Baltic Sea fisheries. Environmental Policy and Governance 20(5):350-363. http://dx.doi.org/10.1002/eet.552

Stöhr, C., and I. Chabay. In press. From shouting matches to productive dialogue: establishing stakeholder participation in Polish fisheries governance. International Journal of Sustainable Development 17(4).

Symes, D., N. Steins, and J.-L. Alegret. 2003. Experiences with fisheries co-management in Europe. Pages 119-134 in D. C. Wilson, J. R. Nielsen, and P. Degnbol, editors. The fisheries comanagement experience: accomplishments, challenges, and prospects. Kluwer Academic Publishers, Dordrecht, The Netherlands. http://dx.doi.org/10.1007/978-94-017-3323-6 8

Thompson, J. L., C. B. Forster, C. Werner, and T. R. Peterson. 2010. Mediated modeling: using collaborative processes to integrate scientist and stakeholder knowledge about greenhouse gas emissions in an urban ecosystem. Society \& Natural Resources 23(8):742-757. http://dx.doi.org/10.1080/08941920802102032

Van den Hove, S. 2006. Between consensus and compromise: acknowledging the negotiation dimension in participatory approaches. Land Use Policy 23(1):10-17. http://dx.doi. org/10.1016/j.landusepol.2004.09.001

Walker, G. B., S. L. Senecah, and S. E. Daniels. 2006. From the forest to the river: citizens' views of stakeholder engagement. Human Ecology Review 13(2):193-202.

Zucker, L. 1986. Production of trust: institutional sources of economic structure, 1840-1920. Research in Organizational Behavior 8:53-111. 